\section{Non-Invasive Treatment of Extensive Eyelid Cancerous Lesion by Photodynamic Therapy: A Case Report}

\section{Abstract}

Cancer of the eyelid represents approximately $10 \%$ of all skin cancer in the head and neck region, and approximately $5-10 \%$ of all skin cancers. Basal cell carcinoma is the most common cutaneous malignancy in the periocular area, accounting for approximately $70-90 \%$ of all cases. The standard treatment for eyelid cancer is surgical excision with reconstruction in case of orbital invasion. Such surgery is involved and in some cases can cause irreversible functional damage to the eye, as well as significant aesthetic and emotional distress for the patient. Photodynamic therapy is a wellestablished technique for the treatment of skin basal cell carcinoma. We therefore propose photodynamic therapy as an alternative treatment of non-melanoma skin cancer and are also indicated as principal option for same types of eyelid cancer.

This is a case report of an eighty three year old patient with a histopathological diagnosis of basal cell carcinoma located in the left eyelid. The patient was treated by topical photodynamic therapy using a cream application of $20 \%$ Methyl-aminolevulic acid, and a fluency of $150 \mathrm{~J} / \mathrm{cm}^{2}$. Clinical evaluation of the patient thirty days after treatment showed a significant clinical response with no evidence of scarring. In addition, no signs of recurrence were observed up to 6 months of follow-up. This clinical case thus showed excellent healing and cosmetic result. In summary, photodynamic therapy is a non-surgical treatment alternative that has the potential to become the number one option for eyelid cancer management, in particular for high risk patients or when surgical resection of highly involved areas is required.

\author{
Ana G Sálvio', \\ Kate C Blanco ${ }^{2}$, Ana P Silva², \\ Hilde H Buzzá2, \\ Natalia M Inada ${ }^{2}$ and \\ Vanderlei S Bagnato ${ }^{2}$
}

1 Amaral Carvalho Hospital Foundation, Jahu, Brazil

2 University of São Paulo, São Carlos Institute of Physics, São Carlos, São Paulo, Brazil

Corresponding author: Vanderlei Salvador Bagnato vander@ifsc.usp.br

Av. Trabalhador São-carlense, 400, São Carlos, São Paulo, Brazil, 13566-590

Tel: $+55163373-9810$

Fax: $+55163373-9811$

Citation: Sálvio AG, Blanco KC, Silva AP, et al. Non-Invasive Treatment of Extensive Eyelid Cancerous Lesion by Photodynamic Therapy: A Case Report. J Aesthet Reconstr Surg. 2016, 1:1.

\section{Introduction}

The most common types of eyelid epithelial cancer are sebaceous carcinoma, squamous cell carcinoma, melanoma, and basal cell carcinoma (BCC), this last one with the highest prevalence (75-90\% of all eyelid tumors). BCC is the most prevalent nonmelanoma skin cancer (NMSC) worldwide [1-3].

The emphasis on treating cancers around the eyelid has been surgical.

Standard treatment of eyelid cancer involves resection surgery followed by skin reconstruction surgery. A major risk associated with this intervention is compromising the functionality of the eye [2]. In addition, the reconstruction of the eyelid is critical for preserving the vision. Therefore, it is expected that the ophthalmic, plastic and dermatological surgeons to be closely involved in such procedures.

Photodynamic therapy (PDT) is a noninvasive treatment that has shown high remission rates for several BCC's cases with excellent results when applied in the early stage of skin cancer [4]. In addition, PDT is a technically simple and noninvasive procedure that offers high level of efficacy and patient satisfaction.

Three elements are necessary in PDT: the presence of a photosensitizer (PS), which is a molecule which absorbs light to initiate a series of photochemical reactions, light at a specific wavelength to be absorbed by the PS, and the availability of molecular oxygen in the treated tissue. The combination of 
compound, light and oxygen results in the production of oxidative cytotoxic agents such as singlet oxygen $\left({ }^{1} \mathrm{O}_{2}\right)$, hydroxyl radical $(\mathrm{OH})$ and others, leading to necrosis, apoptosis and/or autophagy. Methyl aminolevulinate (MAL) is a pro-drug which induces the endogenous PS production and is topically administered to the patient using a transdermal delivery cream. As MAL penetrates in the cells, the aminolevulinic acid induces the production of protoporphyrin IX (PpIX) by mitochondria $[5,6]$.

In this case report, we are presenting the treatment strategy, with the preservation of eye functions and satisfactory aesthetic results.

\section{Case Report}

An eighty-three year old female with superficial BCC with confirmed biopsy $3 \mathrm{~cm}$ width and $4 \mathrm{~cm}$ length in the eyelid region (Figure 1, panel A) was treated with topical photodynamic therapy with 20\% MAL cream (PDT Pharma LTDA. Cravinhos, São Paulo, Brazil). Approval of the Ethics Committee from Amaral Carvalho Hospital (CEPFHAC $n^{\circ} 025 / 11$ ) was obtained and the patient signed a written informed consent form.

After thickness assessment, the lesion was curetted to maximize PDT treatment efficacy and the MAL cream was applied. Three hours after the MAL cream application the region was illuminated for twenty minutes with the commercial device (LINCE ${ }^{\circledR}$, MMOptics, Sao Paulo, Brazil) emitting light at $630 \mathrm{~nm}$ and intensity of $125 \mathrm{~mW} / \mathrm{cm}^{2}$.

Seven days after, a second PDT procedure was performed following the clinical protocol standardized. The patient returned one month after the second session and the clinical cure as well as cosmetic satisfaction assessment of the treated area was obtained. The process was documented by photographs of the treated area using a Sony Digital Camera HSC50.

\section{Discussion}

In this clinical case, a BCC lesion involved the left medial canthus with epithelial invasion into nasal bridge (Figure 1, panel A). The classification of tumor was confirmed by histopathological analysis.

The eyelid preserves the eye against pollutants, keeps the cornea moist [7], and its function is essential for maintaining the eye healthy and vision [8]. The periorbital skin, which protects the eyes, is one of the thinnest cutaneous surfaces of the body, with only $0.6 \mathrm{~mm}$ thickness [9]. The accepted standard treatment for eyelid cancer is resection surgery, which is associated with several ocular complications [10, 11]. Currently, Mohs micrographic surgery is the ideal eyelid cancer removal treatment, in which a dermatologic surgeon generally works with other specialists to the success of treatment [9]. The challenges of eyelid reconstruction following the excision of the eyelid cancer are due to the anatomy and localization of the lesion. In a study performed by Souza et al. [12], the reconstruction of eyelid cancer has resulted loss of eyelid function, and a revision surgery is often required to improve eyelid structure and function $[13,14]$.

The purpose of this report was to present a non-surgical topical treatment that is fast (two sessions, twenty minutes each) and yields excellent aesthetic results, with minimal risk of loss eye functions (Figure 1, panel C). PDT results in photochemical and photo-biological processes which cause irreversible photodamage to the treated tissues [15]. The inflammatory process occurring after seven days following the first PDT session is observed in Figure 1, panel B, which is characterized by enhanced expression of pro-inflammatory cytokines and leukocyte infiltration [16]. The inflammatory response noted in panel $B$ is result of reactive oxygen species in tumor cell in photodinamic reaction. The cellular changes in the nucleus, mitochondria, endoplasmic reticulum and lysosomes results in the loss of cellular integrity. The tumor cell selective PpIX accumulation may be related to high expression of lipoprotein receptors these cells. The lipophilic derivative of aminolevulinic acid (ALA), the MAL may have greater accumulation in the tumor tissue.

Many studies on the efficacy of PDT on BCC have been published $[4,17,18]$. However, only few studies have reported on the topical application of PDT for the treatment of BCC of eyelid cancer $[19,20]$.

The presented clinical case showed excellent cosmetic and functional results (Figure 1, panel C), suggesting that PDT can be advantageous in cosmetically sensitive areas, such as in the face, since treatment of visible lesion can be achieved.
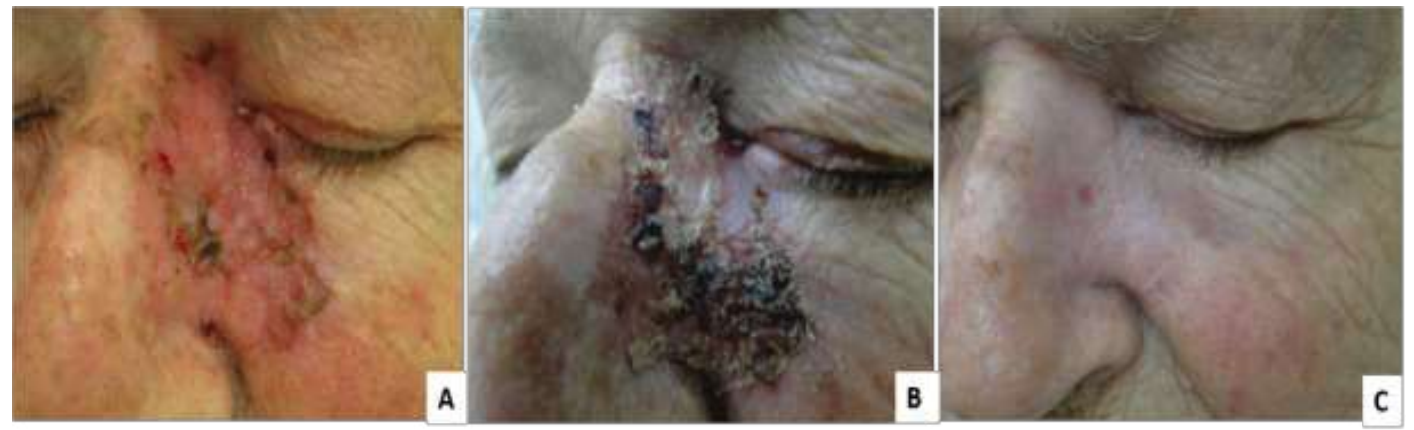
second PDT session. Panel $\mathrm{C}-30$ days after the second PDT session. 
In summary, PDT has been associated with few adverse reactions, good curative rates and cosmetic outcomes. We are presenting a clinical result, which is pointing out PDT as the first option for eyelid cancer management, in particular for a high-risk patient and surgical resection of highly involved area.

\section{Acknowledgement}

Funding for this study was provided by the Brazilian Development Bank (BNDES n ${ }^{\circ}$ 09.2.1458.1); Center of Optics and Photonics (CEPOF $\left.n^{\circ} 2013 / 07276-1\right)$ and the Brazilian Innovation Agency (FINEP). 


\section{References}

1 Azad S, Choudhary V (2011) Treatment results of high dose rate interstitial brachytherapy in carcinoma of eye lid. J Cancer Res Ther 7: 157-161.

2 Rossi R, Puccioni M, Mavilia L (2004) Squamous cell carcinoma of the eyelid treated with photodynamic therapy. J Chemother 16 306-309.

3 Diepgen TL, Mahler V (2002) The epidemiology of skin cancer. Br J Dermatol 146: 1-6.

4 Ramirez DP, Kurachi C, Inada NM (2014) Experience and BCC subtypes as determinants of MAL-PDT response: Preliminary results of a national Brazilian project. Photodiagnosis Photodyn Ther 11: 22-26.

5 Moseley H, Ibbotson S, Woods J (2006) Clinical and research applications of photodynamic therapy in dermatology: Experience of the Scottish PDT Centre. Lasers Surg Med 38: 403-416.

6 Agostinis P, Berg K, Cengel KA, Foster TH, Girotti AW, et al. (2011) Photodynamic therapy of cancer: an update. CA Cancer J Clin 4: 250-281.

7 Delgado-García JM, Gruart A, Trigo JA (2003) Physiology of the eyelid motor system. Ann N Y Acad Sci 1004: 1-9.

8 Harvey DT, Taylor RS, Itani KM (2013) Mohs micrographic surgery of the eyelid: an overview of anatomy, pathophysiology, and reconstruction options. Dermatol Surg 39: 673-697.

9 McLeod M, Zabielinski M, Choudhary S (2012) Mohs Micrographic Surgery for the Eyelid In: Nouri K, ed. Mohs Micrographic Surgery SE. Springer London.

10 Francis IC, Benecke PS, Kappagoda MB (1984) A ten-year hospital survey of eyelid cancer. Aust J Ophthalmol 12: 121-127.
11 Holmström H, Bartholdson L, Johanson B (1975) Surgical treatment of eyelid cancer with special reference to tarsoconjunctival flaps: A follow-up on 193 patients. Scand J Plast Reconstr Surg Hand Surg 9: 107-115.

12 deSousa J-L, Leibovitch I, Malhotra R (2007) Techniques and outcomes of total upper and lower eyelid reconstruction. Arch Ophthalmol 125: 1601-1609.

13 Alghoul M, Pacella SJ, McClellan WT (2013) Eyelid reconstruction. Plast Reconstr Surg 132: 288e-302e.

14 DiFrancesco LM, Codner MA, McCord CD (2004) Upper eyelid reconstruction. Plast Reconstr Surg 114: 98e-107e.

15 Dougherty TJ, Gomer CJ, Henderson BW (1998) Photodynamic therapy. J Natl Cancer Inst 90: 889-905.

16 Gollnick SO, Evans SS, Baumann H (2003) Role of cytokines in photodynamic therapy-induced local and systemic inflammation. $\mathrm{Br}$ J Cancer 88: 1772-1779.

17 Cosgarea R, Susan M, Crisan M (2013) Photodynamic therapy using topical 5-aminolaevulinic acid vs. surgery for basal cell carcinoma. J Eur Acad Dermatology Venereol 27: 980-984.

18 Tope WD, Martin A, Grevelink JM (1995) Lack of selectivity of protoporphyrin IX fluorescence for basal cell carcinoma after topical application of 5-aminolevulinic acid: implications for photodynamic treatment. Arch Dermatol Res 287: 665-674.

19 Report S, Kotimäki J, J. K. (2009) Photodynamic therapy of eyelid basal cell carcinoma. J Eur Acad Dermatology Venereol 23: 10831087.

20 Puccioni M, Santoro N, Giansanti F (2009) Photodynamic therapy using methyl aminolevulinate acid in eyelid basal cell carcinoma: a 5-year follow-up study. Ophthalmic Plast Reconstr Surg 25: 115-118. 